\title{
El oso*
}

Fecha de recepción: 24 de mayo de 2019

Fecha de aprobación: septiembre 28 de 2019

\section{Resumen}

En 2018 el poeta, traductor y editor argentino Miguel Ángel Petrecca publicó una breve biografía del poeta entrerriano Carlos Mastronardi. El relato, fragmentario y aleatorio, intervino los procedimientos y motivos más tradicionales del género: la configuración del archivo, la busca de testimonios y la consecución de un estilo narrativo independizado de la totalización cronológica. Con el propósito de proponer una lectura de Mastronardi, la autora de este artículo expondrá las características experimentales del texto, fundamentalmente en la construcción de las figuras del biografiado, el testigo y el biógrafo; este último, al decir irónico de Juan José Saer: "el hombre que vio al hombre que vio al oso".

Palabras clave: Arnaldo Calveyra; Biografía; Carlos Mastronardi; Miguel Ángel Petrecca; Poesía.

\section{Nora Avaro}

Magister en Literatura Argentina. Profesora adjunta de la Cátedra de Literatura Argentina II, Facultad de Humanidades y Artes, Universidad Nacional de Rosario, Argentina. Universidad Nacional de Rosario

(iDhttps://orcid.org/0000-00025641-6780

*Artículo de investigación 


\section{la palabra}

\section{The bear}

\section{Abstract}

In 2018 the poet, the translator and the Argentinian Editor, Miguel Ángel Petrecca published a brief biography of the Enterrenian poet Carlos Mastronardi. The short story, fragmentary and aleatory, intervened in the most traditional motives and precedents of this literary genre: the archive configuration, the search for testimonies and the consecution of an independent style, away from the totalizing chronology. In this article, I propose a reading of Mastronardi through which I will expose the experimental characteristics of the text, fundamentally, the construction of the figures around the biographized: the witness and the biographer. The latter configured as the ironized figure of Juan José Saer: "the man who saw the man who saw the bear".

Key words: Arnaldo Calveyra; Biography; Carlos Mastronardi; Miguel Ángel Petrecca; poetry. 
Nunca sabremos cómo fue Carlos Mastronardi. ¿Es elegíaca esta certeza? Sí, lo es. Ni el trato con archivos, documentos $\mathrm{y}$ epistolarios, ni la memoria de los informantes, ni la calidad de los testimonios, ni la investigación reglada y la consecuente lectura de la obra completa, le garantizarían, por sí solos, verdad o gradaciones de verdad al retrato virtual de un poeta que además hizo, del escamoteo personal, un método ladino. "Aquí no hay nadie", escribió Mastronardi en sus elegíacas Memorias de un provinciano (1967, p 58). Y, como lo dispuso su admirado Paul Valéry, con trabajo borró las huellas de su trabajo, con trabajo tachó la vida, el azar balzaciano de la vida.

Pero es también elegíaca una segunda certeza, discrepante pero vicaria de la anterior. Aunque nunca sabremos cómo fue Carlos Mastronardi, es evidente que mucha pérdida habrá que lamentar -imágenes, recuerdos, conjeturas - cuando muera su último testigo póstumo, cuando no quede nadie ya que lo haya visto. "Por alguna razón que no podía entender del todo - escribe Miguel Ángel Petrecca en Mastronardi, su breve biografía del poeta, publicada en 2018 - la muerte de A me entristecía menos que la idea de que, con esa muerte, era el mismo Mastronardi el que terminaba de morirse definitivamente" (p.8).
"Nunca sabremos cómo fue James Joyce" —afirmó Juan José Saer en «El concepto de ficción», su ensayo de 1989-. Y agregó:

De Gorman a Ellman, sus biógrafos oficiales, el progreso principal es únicamente estilístico: lo que el primero nos transmite con vehemencia, el segundo lo hace asumiendo un tono objetivo $\mathrm{y}$ circunspecto, lo que confiere a su relato una ilusión más grande de verdad. Pero tanto las fuentes del primero como del segundo - entrevistas y carta - son por lo menos inseguras y recuerdan el testimonio del "hombre que vio al hombre que vio al oso". (Saer, 1989, p. 9)

De Herbert Gorman a Richard Ellman, de uno a otro biógrafo de Joyce, hay - repito y subrayo a Saer - un progreso únicamente estilístico, donde el adverbio no hablaría, como puede pensarse, de una dominante virtuosa sino, muy por el contrario, de una restricción vergonzante. ¿Qué quiere decir Saer acá?, ¿qué quiero yo hacerle decir? En principio, que Ellman escribe progresiva $\mathrm{y}$ objetivamente mejor que Gorman, cuya vehemencia resulta nociva a sus propósitos. Que no hay entre una y otra biografía oficial y oficiosa una variación en calidad de los materiales porque en cuantía vaya si los hay-, sino únicamente en el tratamiento estilístico hacia la circunspección y la objetividad $\mathrm{y}$, por lo tanto, hacia una verosimilitud decisiva: "una ilusión más grande de verdad", escribe Saer (1989, p. 12).

Gorman, el hombre que vio al oso, fue el primero en emprender su biografía. Trabajó en vida de Joyce, se benefició de sus conversaciones con él, con su esposa Nora Barnacle, con su hermano menor Stanislaus. Ellman, por su lado, se sirvió de los acuerdos testimoniales de Gorman, de las notas que Gorman dejó inéditas, de su propio trato con Stanislaus, con Nelly Lichtensteiger viuda de Stanislaus, con los demás hermanos, con los hijos y con los estudiosos de Joyce no hurgados por Gorman a su tiempo. ¿Pero esa progresión estilística de Ellman que, según destaca Saer, deja atrás a Gorman y con él a Joyce interfiriendo en todo y en su posteridad, traería del futuro, o mejor, iría trayendo del futuro, una vida más justa, más próxima a la vida pasada, liquidada de Joyce? La respuesta de Saer es: no. A mayor progreso únicamente estilístico Ellman envicia de impresiones su mesura, extravía su imparcialidad de biógrafo y va quedando por completo bajo el dominio de Joyce: mil páginas de dominación. Y una mayor aun de la que soportó Gorman, quien, patrullado su trabajo por el oso en vida, resultó, para Saer, el más fantasioso de los dos biógrafos. (Un recaudo entre paréntesis: el resaltado 
de la expresión en vida amerita aquí, intenta señalar sus muchos ramales tácitos. No seguiré ninguno, por el momento, pero me importa citar la convicción a la que arribó Benoît Peeters, mientras escribía la vida de Jacques Derrida: "Cada vez lo creo más: no hay biografía sino de los muertos" (2010, p. 143). Del oso muerto. Secuela de lo cual: el hombre que lo vio resultaría mucho menos ineludible que el oso mismo, y su testimonio señero daría un libre y creativo acceso a biografías laterales sobre él).

A medida que pierde distancia, Ellman, según Saer, "va entrando en el aura de Joyce" (1989, p. 11) y, cautivo de ella, termina dando una impresión desagradable. Al dejarse tocar por su biografiado, al no resistirse, como es de rigor, a esa atracción hipnótica, Ellman le provoca a Saer un "verdadero malestar", dicho en sus palabras, y hasta cierta indignación, dicho en las mías.

En el prólogo a la segunda edición de su James Joyce, Ellman escribe: “[...] la elaboración de estas páginas ha renovado todo mi afecto por él" (2002, p. 9); y en la introducción: "El respeto que Joyce provoca al instante se mezcla con un afecto creciente" (p. 23). Me pregunto, le pregunto a Saer: ¿ese respeto instantáneo y ese afecto creciente no serán acaso las fuerzas nodales del estilo biográfico?, ¿no será esa progresión, esa creciente vívida, y únicamente estilística, efecto ineludible del aura del biografiado?, ¿son elegíacas estas preguntas? Sí, lo son.

Es curioso, pero ¡muy curioso!, el rechazo tan epitelial a la fascinación y el afecto de Ellman en nombre de la circunspección y la objetividad, réditos muy extraños al ideal estético de Saer, quien, de inmediato y porque es el propósito excluyente de su artículo, hará una defensa cerrada del "concepto de ficción", lo rescatará de su rudimentaria oposición a la verdad para sumergirlo en las turbulencias de la "«supuesta» realidad objetiva", tan del todo supuesta en esas comillas que deja de serlo. ¿Por qué la ficción podría navegar, y con toda legitimidad, en esas turbulencias gnoseológicas a la busca de verdades complejas, y la biografía, aun las de barcas frágiles, no podría y de ningún modo? Antes de interesarme por la biografía no había notado estas discordias, tan maniobradas ellas por Saer en su encono a la certidumbre referencial y a los señoríos del autor extinto.

Pero treinta años antes, en 1959, el joven Saer reseña encantado My brothers keepers, la obra póstuma de Stanislaus Joyce publicada en 1957. Traduce bien El guardián de mi hermano que, en alguna edición castellana, perdió su gancho bíblico con un título circunspecto y objetivo: Mi hermano James Joyce. Opina por entonces Saer que, a diferencia de los biógrafos profesionales que trabajan con archivos, desenrollan hacia atrás y desde la obra ya hecha, cerrada, la vida de sus autores, y pretenden que una explique la otra y ambas se complementen, Stanislaus escribe la biografía de su hermano solo recordándolo.

Saer aprovecha a señalar, muy precozmente en esta reseña aún no ha publicado En la zona, su primer libro de 1960 - la discrepancia estructural entre memoria y recuerdo, sistémica y voluntaria una, fragmentario y azaroso el otro, y a hacerla funcionar entre la biografía académica, ejemplo de lo general, y My brothers keepers, puro ejemplo particularísimo de sí misma. La memoria documental pertenece al biografismo, el recuerdo al albur del relato fraterno de Stanislaus, cuya familiaridad es, sin duda, su mayor escollo, pero al tiempo su línea promisoria de largada. En nada incomoda a Saer aquí, antes, en 1959, hay que enfatizar la fecha (él mismo la registra al final de su artículo), la posición subjetiva de Stanislaus, como sí, posteriormente, en 1989, la de Ellman ante el ascendiente aurático de Joyce. Al contrario, cuando se trata de la afectación de Stanislaus, la vincula con los avances que la novela "moderna" le imprimió al punto de vista narrativo y al personaje, 
al dotarlos al uno de "coherencia" y al otro de "coherencia", "autonomía" y "convicción psicológica". Más cercano a la tecnología novelesca que al trato disciplinario con documentos e informantes, el relato de Stanislaus gana en contradicciones, oscuridades y, por lo tanto, en realidad; y con los siguientes argumentos poéticos:

Se objetará que el recuerdo no es garantía de exactitud. Esta objeción se basa en la creencia de que los testimonios de una vida pueden ser exactos. Ni la vida de James Joyce —ni la de ningún otro hombre - puede ser contada con exactitud, ni siquiera por el propio James Joyce. La biografía literaria no es una ciencia exacta. Por esa razón es más racional que se proponga ser poética antes que infalible. (Saer, 1959, p. 247)

Richard Ellman, el estilista cooptado y perdidoso de su ecuanimidad que, además, no es de lamentar sino de reprochar, editó póstumamente My brothers keepers. Escribió una "Introducción" generosa que, al correrlo de la sombra de su hermano, pero sin desestimar el vínculo, ilumina el talento de Stanislaus; consiguió la colaboración de T.S. Eliot, a cargo del prefacio; y lo publicó en 1957. Dos años antes que su propia biografía de Joyce, a la que, a lo largo de los años, engordó con nuevos datos en nuevas ediciones. No fueron muchos para un libro de casi mil páginas, pero allí están, dos o tres frases más en cada una. ¿Nuevos datos, enmiendas y precisiones irían a aportar grados de "realidad objetiva", a los recuerdos de Stanislaus y a las turbulencias interpretativas de Ellman? La respuesta de Saer en 1959 y en 1987 es: no.

\section{Poético antes que infalible}

Estimo que Miguel Ángel Petrecca sería tan rotundo como Saer en negar el privilegio disciplinar de los archivos en la escritura de una vida. Necesarios sí, pero nunca excluyentes. Biógrafo experimental de Carlos Mastronardi, Petrecca se propuso, como lo dijo Saer de Stanislaus, ser poético antes que infalible, elíptico antes que integral, entusiasta antes que voluntarioso. Escribió un libro sucinto y pleno, y lo hizo en la dirección aleatoria y progresiva de su estilo, escénico, tonal y fragmentario, y como si sus setenta y cinco páginas, inagotables $\mathrm{y}$ muy afortunadamente capturadas por el aura de Mastronardi, fuesen muchas más que las mil agotadoras del Joyce de Ellman. Narrar la aventura de este oso, el poeta más antiépico de la literatura argentina, le abrió a Petrecca, aunque paradójica, una vía regia a la aventura de narrarlo. Una aventura infalible e inventiva en partes iguales, gracias a la cual, porque nunca sabremos cómo fue Carlos
Mastronardi, podemos imaginarlo tal cual fue.

Petrecca es breve pero, como todo biógrafo que se precie, de grandes, balzacianas ambiciones. No solo aspira a biografiar a Mastronardi sino también a hacerlo visible, a retratarlo, en el sentido mimético y plástico del término. Petrecca quiere ver al oso, ser el imposible hombre que vio al oso; y quiere proyectar esa visión. De hecho, su libro se inicia con dos imágenes que, mediadas ambas, precisan el punto de miras del biógrafo. La primera, el poeta en la mesa de un bar divisado por un amigo de Petrecca; y enseguida, la segunda, el poeta y el gato, observados por Petrecca en una foto bastante célebre - en sus rendimientos provincianos, claro está- que, además, dibujada en tinta y lápiz, ilustra en tapa el título del libro, su denotación circunspecta: Mastronardi. "Hay que verlo" y "hay que imaginarlo", escribe Petrecca. Un par de edictos que son, también, régimen, anhelo e ideal biográficos, en estado de gracia narrativa. "Hay que verlo a Mastronardi sentado en la cocina de su casa, de noche, mate en mano, corrigiendo por enésima vez una estrofa, cambiando una coma de lugar, dedicándose a la cacería del verso perfecto" (Pertrecca, 2018, p. 16); y "hay que imaginarlo, digo, en las noches de la primera mitad de la década del 30, inclinado sobre la mesa en la cocina de la casa, 
inmóvil frente a la página llena de tachaduras" (p. 16). De la letra a la visión y de la visión a la imaginería. Al cumplir el más aventurado de los trances biográficos, y el más legítimo, Petrecca suma y ajusta los megapixeles de su figura metódica y elegíaca en dos hitos proverbiales: las rutinas nocturnas y el arrebato enmendador de Mastronardi, y logra alumbrar con ambos el designio autobiográfico de "Luz de provincia", el poema más rectificado de la literatura argentina. "Volvía con inquietud al principio, dispuesto a rehacerlo todo", escribe Mastronardi en sus Memorias de un provinciano (1967, p. 98).

El ingenio visual de Petrecca opera por secuencias y, en una suerte de corriente alterna, va cambiando de dirección y magnitud. Tiene, al menos, dos fechas factibles de inicio: la de la historia y la de la biografía, la vida de don Carlos Mastronardi se juega entre ellas. Una: 1949 , cuando Arnaldo Calveyra, el otro poeta entrerriano del relato, "el hombre que vio al oso", conoce a Mastronardi en el colegio nacional de Concepción del Uruguay del que ambos, con una diferencia de años, son egresados. Y la otra: 1971, cuando el amigo de Petrecca lo ve a Mastronardi sentado a la mesa de un bar de la Avenida de Mayo, en Buenos Aires, y Petrecca, que lo escucha en un presente indatable, se vuelve, aún sin proponérselo, y sobre todo aún sin saberlo, un biógrafo, es decir: "el hombre que vio al hombre que vio al oso". Digo al menos estas dos fechas referenciadas, 1949 y 1971, porque el tiempo de la narración es fortuito, tornadizo y completamente ocasional. Se entiende, entiendo yo, que en menoscabo de la cronología, la avidez totalizante y la motivación como garantes de un destino.

Contra esas garantías, y contra las reservas de exhaustividad que ellas suponen, Petrecca avanza sin plan sistemático y por aproximación, la brevedad episódica de su biografía es resultado de estas decisiones, no su premisa. Redondea y generaliza la vida de Mastronardi, en décadas paseanderas, "Caminatas de a dos. Pares que caminan", escribe. En los años diez del siglo xx, Mastronardi camina Gualeguay con Juanele, en los veinte camina Buenos Aires con Borges, en los treinta vuelve a caminar Gualeguay con Juanele, en los cincuenta vuelva a caminar Buenos Aires, ahora con Calveyra. Estas marchas, de distintos ritmos y topografías, de distintas charlas y silencios, trazan para Petrecca, un arco de vivencias: desde la camaradería provinciana y, luego, vanguardista, a la denegación del magisterio. "Los suyos no son los silencios solemnes de un maestro - escribe Petrecca sobre el Mastronardi de los años cincuenta, el Mastronardi de Calveyra-, sino los de al- guien incómodo con cualquier magisterio: los silencios de un saboteador" (p. 35 ).

El redondeo sumarial de Petrecca anexa otros tópicos de vida a esta primera vida de pares callejeros, y pueden catalogarse, en las distintas décadas señaladas, como leit motivs estructurales: las mudanzas y los viajes (Gualeguay, Concepción del Uruguay, Buenos Aires, Montevideo, Tucumán, Mar del Plata, Río de Janeiro), los amores (Eduarda, Valentina), los trabajos (el periodismo, la burocracia estatal), los libros (reales y dudosos). Son, más que sucedidos conspicuos, el telón de fondo sobre el cual iluminar escenas que, además, no guardan con ellos ningún lazo narrativo culminante $\mathrm{y}$ en las que van variando los protagonismos: el biógrafo, los amigos del biógrafo, los amigos de los amigos del biógrafo, la mujer del biógrafo, el oso, los amigos del oso, las mujeres del oso, los testigos innominados del oso entre estos últimos: la resentida, el que tiene Alzheimer, la que entró a la habitación del oso, el informante de la sigla $\mathrm{A}$ Estas tranches de vie, de esas varias vidas, no trascienden su puesta en acto, no son parte manifiesta de ningún resto latente, enaltecido por las burocracias del secreto. No hay en Petrecca sinécdoque biográfica ni instancias de revelación. De hecho y de entrada nomás, en la primera página de su Mastronardi, 
se preserva de los hallazgos y puntualiza, en un fraseo corto, su ciencia de biógrafo: "Nada se oculta, sin embargo. No hay secreto. Nada que revelar. La imagen es hueca" (2018, p. 8).

La vida del poeta provinciano no traza su línea de causalidades ni su efectuación crucial. Casi todo lo que interesa de Mastronardi, lo que a Petrecca le interesa de Mastronardi, carece de derivas y fundamentos exegéticos. En lugar de secuencias de largas tiradas, hay encuadres más bien antojadizos y, si aún cabe el brillo de alguna epifanía en esta apuesta fiel por la contingencia y el medio tono, que habrían contentado en mucho a Carlos Mastronardi, es solo la que provocan las imágenes:

En el patio de esa casa, un 7 de octubre de 1909, día de su cumpleaños, miró con intensidad el cielo de la tarde y le quedó grabado para siempre el color de la luz, el color del cielo. Esa pequeña epifanía es una de las experiencias decisivas en la vida de Mastronardi. (Petrecca, 2018, p. 25)

La única, además, la que en el enlace mítico de la vida y de la obra le pone título a "Luz de provincia", el poema más célebre del oso.

Por deber de ilustrar lo que digo pero más por el agrado de montarlas, acá van algunas de esas imágenes sin remanente, satura- das sobre el fondo sumario de décadas y redondeos. Mastronardi y Borges caminan tan entretenidos por el suburbio porteño que tardan en darse cuenta de que están chapoteando en el barro; Mastronardi llega en barco a Concepción del Uruguay a cubrir el centenario del Colegio Nacional y se queda dormido en el camarote; Mastronardi le escribe una carta a Valentina, su mujer, le recuerda la mesa que ocupaban en la confitería Nobel; Mastronardi y Calveyra se bañan en el río Uruguay al mediodía; de vacaciones en Mar del Plata, Mastronardi y Bioy Casares intentan y fracasan en escribir a cuatro manos un cuento policial; Calveyra visita a Mastronardi en su casa de la calle Thorne al 400, en Buenos Aires, salen a caminar por los alrededores, de a ratos Mastronardi enmudece; desde el balcón de la casa que comparte con Valentina en Río de Janeiro, Mastronardi observa con el telescopio de su padre los vapores del día y las estrellas de la noche; de visita a la casa materna en Gualeguay, atrapado por la inundación, Mastronardi va hasta el río, se fascina con los remolinos de ramaje que la corriente arrastra aguas abajo; desde el cuarto piso del hotel Astoria en la Avenida de Mayo, donde vive solo hacia fines de los años sesenta, Mastronardi observa dormir a una mendiga; Mastronardi hace la cola en la redacción del diario El Mundo para obtener un vale de comida; en 1975, pocos meses antes de morir, Mastronardi espía por una ventana la antigua casa de sus abuelos en Gualeguay.

Petrecca hace una única visita al lugar de los hechos, o al menos esa es la que le importa contar. Sus lectores ignoramos si viajó a Gualeguay, pasó por la calle Thorne en Buenos Aires o por la calle Vizconde de Ouro Preto en Río de Janeiro. Sabemos sí que, en 2015 , al volver al país después de dos años de ausencia, Petrecca va al Hotel Astoria, probablemente porque le queda de paso, más a mano que Brasil, Entre Ríos o el barrio porteño de Flores, pero también porque lo mueve otra imagen, una más, la misma que atrae a Mastronardi, al punto de registrarla en sus Cuadernos, más bien remisos estos a los hechos cotidianos. "La mendiga metafísica" duerme a la intemperie frente al hotel y desaparece prolijamente por las mañanas:

Después de dormir en el fragor del tránsito - escribe Mastronardi-, la vagabunda alza los papeles que le sirven de colchón y empieza a caminar. Siempre vuelve al sitio elegido. Pordiosera metafísica, sospecho que se salva del infinito mediante un orden que le permite reconocerse y esquivar el abismo". (1984, p. 88).

Petrecca dedica un capítulo a protagonizar la excursión al Astoria, con algunos episodios 
mechados, como ya es su estilo poético e infalible de dejarse llevar, en este caso: de la pordiosera a la Avenida de Mayo, de la metafísica a la realidad. Y aunque no confía obtener mucho de esa visita, obtiene todo lo que importa: el acto de contarla en una vida de Mastronardi. El hotel ha cambiado de dueño y de estatus varias veces, los registros se han perdido, el empleado más antiguo está muerto. Nadie en el Astoria vio al oso. Pero el oso estuvo ahí, en la ventana del Astoria, en la escalera del Astoria. El fantasma cooptante del oso y su mendiga.

\section{T2 Una langosta que lee}

De la pasión, esta sí totalizadora de Claudia Rosa y Elisabeth Strada, las editoras de la Obra completa de Carlos Mastronardi (2010), Petrecca se aprovecha como del mejor archivo; aquel que es necesario arquear primero, para reconfigurarlo de inmediato en cada impulso de la curiosidad o exigencia de verosimilitud. La obra, poemas, memorias, artículos, traducciones, cuadernos y libros de edición póstuma, los ensayos sobre la obra y la correspondencia, las cartas que Matronardi le envía a Calveyra, convenientemente tachadas por el destinatario, todo reunido en una publicación, es el dispositivo necesario (pero nunca excluyente) para construir fuentes y activarlas: seleccionar contenidos y citas, ajustar períodos y elipsis, en- samblar episodios y, sobre todo, capitular ante el monumento. Es claro que, esto último, Petrecca lo hace resuelto y sin penar.

A la familiaridad con la obra del oso, esas dos mil páginas que, tras su gestión biográfica, revertirán en setenta y cinco, Petrecca agrega algunos cuentos de los que lo trataron. Todos facilitan la visión y la imaginería: uno vio a Mastronardi en la redacción de El Mundo, otra lo vio en su habitación de hotel. Aunque casi huecos de datos concretos, dos de esos testimonios montan finos circuitos de figuración escénica, que Petrecca va a hacer rendir más que cualquier primicia. Uno, el testimonio "vacío" de la esposa de un discípulo de Mastronardi que, después de darle varias vueltas a su resentimiento y servir café, le repite a Petrecca un dicho, el mejor autorretrato sintético del oso por siempre jamás: "Soy una langosta que lee". Como se puede ver sin siquiera intentar comentarla, la imagen viene a notificar, en su potencia plástica, más que una estantería de documentos. El otro, el testimonio "agujereado", de la sigla A. Las varias entrevistas a A grabadas en bares, donde el ruido ambiente las inutiliza o donde el propio A las esquiva, le dan a Petrecca los visos de un proceder y de una afectación, la del hombre que vio al oso, que admiró al oso, y que quiere tutelar, más que al oso mismo, la posteridad de esa visión.
En uno de los grandes momentos de cualquier proceso biográfico, uno de esos que merecían, por sí solos, una autobiografía del biógrafo, Petrecca se encuentra, después de la muerte de $\mathrm{A}$, de que A ya no tenga dominio sobre él, con el secreto y codiciado archivo Mastronardi de A. Pero... un pero muy amplio, uno en el que caben las destrezas y las mañas biográficas de este librito, a la ansiedad por revisar esos papeles y dar allí con las respuestas que, siempre tangencial, A habría eludido en vida, le sobreviene la decepción más absoluta. Petrecca lo dice así:

Cómo había podido aguantarme la ansiedad esos días, luego de que su mujer [la mujer de A.] me comunicara por teléfono la existencia de esa carpeta, porque al saberlo no había podido evitar imaginar que en su interior se encontraba algo no sé bien qué, la respuesta a las preguntas que no había hecho. Pero en el fondo, todo el tiempo sabía que no había nada que esperar de esa carpeta, ni de ningún papel o archivo que pudiera encontrarse eventualmente en esa casa. (2018, p. 56).

Nada que esperar. Ningún hallazgo en el archivo. Y no solo por las censuras a las que A. sometió los papeles y aún las cartas que entregó para la edición póstuma de la obra de Mastronardi, párrafos enteros tachados con minucia, sino porque "No 
hay secreto. Nada que revelar. La imagen es hueca" (p. 8).

\section{A de Arnaldo}

Yo iba a presentar este librito de Petrecca en la ciudad de Santa $\mathrm{Fe}$, en un ciclo de Poesía del Litoral que curó Martin Prieto en 2018, pero me caí de una silla, me quebré la muñeca y no pude viajar. Había escrito una reseña entusiasta para la revista $\tilde{\mathrm{N}}$ del diario Clarín. Sabía y sé poco de la vida de Petrecca, apenas algo más de lo que informa la solapa de su Mastronardi: que es poeta, traductor del chino, codirige la editorial Gog y Magog, vive en París, donde regentea una librería. Como es de rigor en las vidas de los creyentes en las vidas de escritores, estaba interesada en el oso (tenía mi propia devoción y mi propio escrito sobre Mastronardi), y bastante menos en su biógrafo. Porque ¿quién vendría siendo Ellman al lado de Joyce o Lottman al lado de Flaubert, no?, para listar solo dos ladrillos colosales, falibles y tampoco poéticos. Pero, también lo contrario: ¿quién Evaristo Carriego al lado de Jorge Luis Borges, no?, ¿quién la reina Victoria al lado de Lytton Strachey? (este es un chiste). De uno u otro lado, da igual, porque en esa distracción se me perdió un dato: Petrecca es, era, amigo de Arnaldo Calveyra, caminante discipular de Mastronardi en la redondeada década del cincuenta.
Calveyra aparece en el libro de Petrecca, uno: con su propio nombre y apellido; dos: bajo la sigla A. Esta doble apariencia no se aclara nunca, de modo que parecen ser personajes diferentes: el primero, civil y literariamente certero (Arnaldo Calveyra); el segundo, enigmático (A). Que, en realidad sean uno y el mismo me lo aclaró Petrecca vía mail, y prometió justificar esa doble identidad en el acto que nos reuniría en Santa Fe. Como no fui y me la perdí, puedo proseguir liberada sobre esa justificación.

Es claro, era claro aun cuando no supe verlo, que el Mastronar$d i$ de Petrecca está escrito casi enteramente sobre el testimonio de Calveyra, que Calveyra en París le contó a Petrecca sus recuerdos de Mastronardi, casi como los de Stanislaus Joyce, pero mejor, libre de las extorsiones familiares. Me pregunto sin respuesta cierta, sólo, como corresponde, para que la pregunta perdure, ¿le habrá dado Calveyra a Petrecca, además de anécdotas, la melodía para contarlas? "Un testimonio solo es verdadero en el momento de ser pronunciado o escrito", escribió Calveyra al inicio de su Diario francés, y también "Cada cosa es verdadera al principio" (2017, p. 9). ¿Tomó nota Petrecca de la contundencia de este fallo, de los tiempos que imputa? Ahora no lo sé, pero sé por fuera del libro de Petrecca, lo sé en, cómo decirlo, la realidad, de su amistad con Calveyra, y ya no puedo prescindir de ese saber.

En el libro, Petrecca metió dos personajes. El que acompañó al oso y el que le habló del oso antes de morir. La muerte de A se cuenta apenas iniciado el libro, y es su disparador: "Pensé en Mastronardi ese día mientras caminaba alrededor de un lago congelado, tras enterarme de la muerte de A - escribe Petrecca-. Pensé en A que acababa de morir sorpresivamente a miles de kilómetros" (2018, p. 10); y se retoma al final y es su cierre: "Vuelvo a la tarde en que mi mujer me contó por teléfono, mientras yo caminaba alrededor de un lago congelado, a miles de kilómetros de distancia, la noticia de la muerte de A." (p. 60).

Como A es seguramente uno de los últimos que vio al oso, que tiene una imagen del oso, ejercida en la poética de su recuerdo, Petrecca tal vez desee sobre todo, y tal vez más que biografiar a Mastronardi, conservar los recuerdos del amigo A en una línea de tiempo discipular (ver: Avaro, 2020). Su interés en ese caso sería doble y hasta triple, o mejor, un interés tras otro: la vida del oso, tras la vida del que vio al oso, tras la vida del que vio al que vio al oso. Es palmaria esta triple gravitación en el artificio biográfico, y es rara. Es como si al contar la vida de Mastronardi, Petrecca también quisiera traer la de su 
informante y, por esta vía transitiva, la suya propia, todas en un estado oscilante de afectos, de afecciones renovadas. Mastronardi incluye en tanto biografía experimental, y en un escrutinio rápido no conozco otra que lo haga con esta magnitud, además de las andanzas del biografiado y las del biógrafo en primera persona de entrada nomás, la del testigo ocular privilegiado en tercera persona subordinada ("Tengo un amigo que un día de 1971 vio a Mastronardi", $p$. 7), necesario, en todo caso, para darle nitidez plástica y poética al retrato: "Hay que verlo", "hay que imaginarlo", quiere Petrecca.

Es por esta razón que aquí los testimonios se entrecomillan poco - poco está la voz en bruto de Calveyra si esto fuera posible, y no lo es - sino que se transforman en escenas, imágenes de conversación, ganan en ese atajo fibra evocativa $y$, de paso, pero no al margen, atienden la lección de Calveyra: "un testimonio solo es verdadero en el momento de ser pronunciado o escrito". ¿Cómo hacer esto?, ¿cómo perderse la temperatura de la voz de Calveyra?, ¿cómo compensarla para serle fiel? Desdoblando su presencia en la vida de Mastronardi. Aquí un pasaje del libro que muestra, contiguas, una y otra aparición:

Entre 1950 y 1960 Calveyra viaja desde La Plata casi semanalmente para encontrarse con Mastronardi. Mastronardi lo había acogido enseguida, desde aquel encuentro en Concepción del Uruguay, cuando Calveyra se le acercó lleno de fervor discipular, pues se acercaba al poeta que había escrito «Luz de provincia». Se acercó, aprovechando la oportunidad trivial que los había hecho coincidir en un mismo lugar y momento: la conmemoración de los 100 años del colegio del que ambos habían egresado, uno varias décadas atrás, el otro pocos años antes. Por lo que me dijo A una de las veces que charlamos, en uno de esos cafés ruidosos que apenas dejaban pasar su voz, Mastronardi había viajado en barco desde Buenos Aires a Concepción del Uruguay la vez que coincidieron en el 49. (Petrecca, 2018, p. 46)

Subrayo en itálicas el pasaje de Calveyra a A, y la escena, charla en un café ruidoso, en una misma línea de puntos seguidos. Es donde sintáctica y narrativamente se encuentran Calveyra y A, y donde pueden confundirse si se interpreta, como yo no lo hice a tiempo, que el cuento en tercera persona de Calveyra esconde indirecta y libremente la primera persona de A, A de Arnaldo, de Arnaldo Calveyra.

\section{Un modesto poeta elegíaco}

En mi intercambio de correos electrónicos con Petrecca, le pregunté si había visto el cortometraje Luz de provincia, que
Lito Muravchik editó en 1972. Se rueda en 1971, el año fundacional de este librito, en que el amigo de Petrecca vio al oso en un bar de la Avenida de Mayo. No encontré ningún otro dato relevante en google de Muravchick como director de cine, solo que hoy, en un hoy tan extenso como google, vende seguros para filmaciones. Le copié el link de Luz de provincia a Petrecca, está en Vimeo (https:// vimeo.com/145948026). Le dije que me había conmovido el backstage que, con mucho tino, Muravichk incluyó en el inicio de su película. Es una gran idea, opacada después un poco por la película propiamente dicha, que ilustra la voz en off de Mastronardi leyendo el poema célebre con paisajes de Entre Ríos, locaciones biográficas (la casa natal, las calles de Gualeguay, las calles de Buenos Aires) y el estar ahí de algunos personajes vestidos al uso local, al uso que Muravchik considera local, y que parecen medio disfrazados. Pero qué importancia tendrían estos detalles frente a la felicidad de escuchar y ver al oso en persona. En lo que me importa ahora, el backstage. Mastronardi está sentado a una mesa de bar, con un café servido y un vaso de agua. La cámara está fija en un plano medio de su figura, de manera que nos da a los espectadores la ilusión de estar sentados frente a él. Tiene unas orejas grandísimas y labios muy finitos, el marco cuadrado y amplio de los anteojos se 
posa sobre las mejillas y hecha sombras sobre sus párpados. El ruido ambiente, ensordecedor casi, como el de los cafés donde se encontraban Petrecca y Calveyra, también nos da la misma ilusión de estar sentados frente a él. El fotógrafo, un preliminar Carlos Sorín, mide la luz de la escena, el fotómetro tapa el rostro de Mastronardi. Asistentes cruzan delante de la cámara, uno le pide "Se seca un poquito, don Carlos", y don Carlos saca un pañuelo del bolsillo superior del saco y se seca la transpiración de la barbilla. Otro le pregunta “¿Cómo se siente?” y él responde: "Muy bien, muy bien, un poco encandilado por estas luces inhabituales para mí, pero muy bien". Un tercero pide silencio para rodar la toma $2 \mathrm{de}$ la escena 14. Mastronardi está expectante ante el micrófono, preparado como en una línea de largada, para recitar de memoria, al anuncio de acción, y con una carencia de gracia natural realmente extraordinaria, lo que sigue ("hay que verlo", y "hay que imaginarlo"): Auna pregunta suya yo me
definí como un periodis-
ta jubilado, pero bromas
aparte, podría decir tam-
bién que podría definirme
como un modesto poeta
elegíaco o más bien como
un representante modesto
de la pálida serenidad de
Entre Ríos. De todos mo-
dos, aparezco determina-
do por el medio natal, es

decir, por esa provincia a la que un fresco abrazo de agua define para siempre. (Muravchik, 1972)

Del modesto poeta elegíaco a la langosta que lee, de la denotación adjetivada a la imagen, en esa distancia figurativa entre dos autorretratos cabe la vida breve de Carlos Mastronardi.

Petrecca no me contestó el mail que le escribí con el link a la película Muravichk, supongo porque ya esperó que nos viéramos en Santa Fe, pero también supongo porque no le interesó, realmente, ver a Mastronardi, sino más que en las palabras de A., de Arnaldo Calveyra, "Cada cosa es verdadera al principio".

\section{Referencias}

Avaro, N. (2020). “Carlos Mastronardi y Arnaldo Calveyra. ‘Cómo se aprende a escribir un poema?”” en Afinidades. Revista de la Biblioteca Nacional, N 16, Montevideo, Uruguay.

Calveyra, A. (2017). Diario Francés. Vivir a través del cristal. Buenos Aires: Adriana Hidalgo editora.

Ellman, R. (2002). James Joyce. Barcelona: Anagrama.

Mastronardi, C. (1967). Memorias de un provinciano. Buenos Aires: Ediciones Culturales Argentinas.

Mastronardi, C. (1984). Cuadernos de vivir y de pensar (1930-1970). Buenos Aires: Academia Argentina de Letras.

Muravichk, L. (1972) Luz de provincia (cortometraje). Entre Ríos, Argentina: Fondo Nacional de las Artes. Recuperado de https://vimeo.com/145948026

Peeters B. (2010). Trois ans avec Derrida. Les carnets d'un biographe. Mayenne, France: Flammarion. 
Petrecca, M. (2018). Mastronardi. Rosario, Argentina: Neutrinos.

Rosa, C. y Strada, E. (edits.). (2010). Mastronardi. Obra completa. Tomo I y II. Santa Fe, Argentina: Ediciones UNL.

Saer, J.J. (1989). "El concepto de ficción” en El concepto de ficción. Buenos Aires: Espasa Calpe / Ariel, 1997.

Saer, J.J. (1959). "El guardián de mi hermano" en El concepto de ficción. Buenos Aires: Espasa Calpe / Ariel, 1997.

\section{AR'TICULOS RECOMEDADOS}

Musitano, J. (enero-junio de 2017). El problema del nombre. Los casos de Jorge Baron Biza y Julián Herbert. La Palabra, (30),23-34. đoi https://doi.org/10.19053/01218530.n30.2017.6209

Pinilla Monroy, M.C. (enero-junio de 2015). Emily Dickinson: instantáneas del abismo. La Palabra (26), 139-149. 여 $\mathrm{https} / /$ doi.org/10.19053/01218530.3254 